\title{
A prospective study to evaluate the role of hysterolaparoscopy in infertility
}

\author{
Pooja Subhash Kale ${ }^{1 *}$, Sylvia Noronha ${ }^{2}$
}

\begin{abstract}
${ }^{1}$ Department of Obstetrics and Gynecology, Bharti Hospital, Pune, Maharashtra, India
${ }^{2}$ Department of Obstetrics and Gynecology, Holy Family Hospital, Bandra, Mumbai, Maharashtra, India
\end{abstract}

Received: 09 July 2018

Accepted: 02 August 2018

\section{*Correspondence:}

Dr. Pooja Subhash Kale,

E-mail: drpoojakale87@gmail.com

Copyright: () the author(s), publisher and licensee Medip Academy. This is an open-access article distributed under the terms of the Creative Commons Attribution Non-Commercial License, which permits unrestricted non-commercial use, distribution, and reproduction in any medium, provided the original work is properly cited.

\begin{abstract}
Background: Infertility is one of the most important and underappreciated reproductive health problems in developing countries. The aim of the present study was to evaluate the role of hysterolaparoscopy in infertility.

Methods: It was observational prospective study. In this study, 50 patients in the age group of 20-40 years who are anxious to conceive formed the study group. All women were subjected to a detailed history taking followed by clinical examination.

Results: Out of 50 cases studied, $30(60 \%)$ were of primary infertility while, $20(40 \%)$ were of secondary infertility. Laparoscopic findings were as follows, $28 \%$ had polycystic ovaries, $20 \%$ had endometriosis, $18 \%$ had tubal factors, $18 \%$ had adhesions, and $8 \%$ had fibroids while $4 \%$ had PID. Hysteroscopic findings were uterine septum in $16 \%$, T shaped cavity in 14\%, shaggy-hyperplastic endometrium in $10 \%$ while adhesions and polyps in $8 \%$ and $4 \%$ respectively. 16 women $(32 \%)$ conceived after the procedure during the study period.

Conclusions: It is concluded that while investigating the causes of female infertility combined simultaneous diagnostic laparoscopy and hysteroscopy with operative interventions wherever indicated should be performed in all infertile patients before treatment, especially in women with age more than 30 years.
\end{abstract}

Keywords: Hysterolaparoscopy, Infertility, Primary infertility, Secondary infertility

\section{INTRODUCTION}

Infertility is one of the most important and underappreciated reproductive health problems in developing countries. In our country there is also a social stigma associated with infertility. As a result, there is an ever-increasing demand for diagnostic and therapeutic intervention for the management of infertile couple. It has been estimated that in India $10-15 \%$ of the couples are infertile.

Hysterosalpingography and laparoscopy are the two classic methods for evaluation of tubal factors and are complementary to each other rather than mutually exclusive. Laparoscopy is generally regarded as definitive test for evaluation of tubal factors. It provides both panoramic view of pelvic reproductive anatomy and a magnified view of uterine, ovarian, tubal and peritoneal surfaces and its pathology. It can confirm a clinical impression, establish a definite diagnosis, follow the course of a disease, and modify therapy. Certain operative procedures (ovarian cyst aspiration or biopsy of intraperitoneal structures) can be accomplished through the laparoscope. ${ }^{1}$

Therefore, laparoscopy is an important tool to assess the reproductive pathology including tubal patency (chromopertubation) in infertile women. In the same setting therapeutic interventions like adhesiolysis, PCO drilling, cystectomy etc can be performed in these 
patients. Thus, laparoscopy offers both diagnostic and therapeutic advantage to the infertile patients. Since morphological abnormalities of the Fallopian tubes can be visualized directly under laparoscopy, it is generally accepted as the gold standard in diagnosing tubal pathology and other intra-abdominal causes of infertility.

Hysteroscopy provides direct visualisation to the interior of the uterine cavity thus leading to diagnosis of various anomalies, synechiae, and tubal block. It can be used as therapeutic tool as well (procedures like metroplasty, tubal cannulation, adhesiolysis). Thus, combined use of hysterolaparoscopy provides a comprehensive investigative and therapeutic procedure in which various factors causing female infertility can be assessed in a single setting. The study was undertaken to analyse various pathological conditions in the female reproductive tract leading to infertility and to evaluate the role of hysterolaparoscopy in the management of infertility.

\section{METHODS}

The study was carried out at the department of Obstetrics and Gynaecology, Holy Family Hospital, Bandra. It was observational prospective study. In this study, 50 patients in the age group of 20-40 years who are anxious to conceive formed the study group. It is an observational prospective study which was carried out over a period of 15 months, from June 2013 to August 2014. All women were subjected to a detailed history taking followed by clinical examination. Those cases where investigations like husband's semen analysis, hysterosalpingogram and ultrasonogram have been done before the surgery were taken for the study.

\section{Inclusion criteria}

- Women in the age group of 20 to 40 years

- Primary or secondary infertility

- Normal husband semen analysis.

\section{Exclusion criteria}

- Patients not giving consent for study

- Patients with severe medical illness deferring general anesthesia.

Hysterolaparoscopy was performed in the follicular phase of menstrual cycle. Findings of the cases undergoing the hysterolaparoscopy and operative interventions if any were noted. Hysterolaparoscopy was performed under general anesthesia and the patients were kept for a period of 24 hours in the hospital post-operatively. Surgical interventions were carried out whenever required. First, hysteroscopy was performed to visualize panoramic view of the uterine cavity, ostia, endocervical canal and then observations made on laparoscopy were systematically recorded.
The pelvic cavity was visualized for any gross abnormality followed by visualization of pelvic organs namely uterus, fallopian tubes, ovaries, pouch of Douglas (for any endometriotic deposits) and finally tubal patency test with methylene blue was performed. Correction of the abnormalities if any was attempted for example polycystic ovarian drilling in cases of PCOD, tubal cannulation in cases of proximal tubal occlusion, ovarian cystectomy, metroplasty in cases of hypoplastic uterus or $\mathrm{T}$ shaped uterine cavity. Patients were followed up over a period of 15 months to observe the improvement in fertility outcome. The data collected was subjected to appropriate statistical analysis.

\section{RESULTS}

Table 1 revealed that $36.7 \%$ of the cases had $1^{\circ}$ infertility that were among age group 25-29 years and 30-34 years whereas $45.0 \%$ of the cases who had $2^{\circ}$ infertility were in age group of 30-34 yrs. Average age among the cases that had $1^{\circ}$ infertility was 31.17 years which was comparable to 31.55 years among the cases who had $2^{\circ}$ infertility.

Table 1: Age wise distribution of infertility among study cases.

\begin{tabular}{|c|c|c|c|c|c|}
\hline \multirow{3}{*}{$\begin{array}{l}\text { Age } \\
\text { group } \\
\text { (years) }\end{array}$} & \multirow{3}{*}{ No. of cases } & \multicolumn{4}{|c|}{ Infertility } \\
\hline & & \multicolumn{2}{|c|}{$\begin{array}{l}1^{\circ} \\
(\mathrm{N}=30)\end{array}$} & \multicolumn{2}{|c|}{$\begin{array}{l}2^{\circ} \\
(\mathrm{N}=\mathbf{2 0})\end{array}$} \\
\hline & & No & $\%$ & No & $\%$ \\
\hline $20-24$ & 05 & 01 & 03.3 & 04 & 20.0 \\
\hline $25-29$ & 12 & 11 & 36.7 & 01 & 05.0 \\
\hline $30-34$ & 20 & 11 & 36.7 & 09 & 45.0 \\
\hline $35-40$ & 13 & 07 & 23.3 & 06 & 30.0 \\
\hline $\begin{array}{l}\text { Average } \\
\text { age }\end{array}$ & $31.32 \pm 04.64$ & \multicolumn{2}{|c|}{$31.17 \pm 04.50$} & \multicolumn{2}{|c|}{$31.55 \pm 04.97$} \\
\hline
\end{tabular}

Table 2: Duration of infertility with profile of obstetric history among study cases.

\begin{tabular}{|lll|}
\hline Items & No. of cases & $\%$ \\
\hline Duration of infertility (years) & \\
\hline $1-5$ & 32 & 64 \\
\hline $6-10$ & 14 & 28 \\
\hline $11-15$ & 03 & 6 \\
\hline $16-20$ & 01 & 2 \\
\hline Obstetric history & & \\
\hline Previous abortions & 16 & 80.0 \\
\hline Previous full-term deliveries & 07 & 35.0 \\
\hline Previous IUD & - & - \\
\hline Previous pre-term deliveries & - & - \\
\hline
\end{tabular}

For Duration of infertility (years) most of studied cases fall in of 1- 5 years of infertility (32) followed by 6-10 years (14). Lowest number of cases was reported in 11-20 years of infertility.

As per Table 2, $80.0 \%$ of the cases had Previous abortions followed by $35.0 \%$ of Previous full-term 
deliveries. There were few women with both previous abortion as well as previous full-term deliveries.

According to above Table 3, 28.0\% of the cases had PCOD followed by $20.0 \%$ who had Endometriosis and $18.0 \%$ each had Tubal factors and Adhesions on laparoscopy followed fibroids $8 \%$ and PID $4 \%$.

Table 3: Profile of laparoscopic findings.

\begin{tabular}{|lll|}
\hline Laparoscopic findings & No. of cases $(\mathrm{N}=50)$ & $\%$ \\
\hline PCOD & 14 & 28.0 \\
\hline Endometriosis & 10 & 20.0 \\
\hline Tubal Factors & 09 & 18.0 \\
\hline PID & 02 & 04.0 \\
\hline Fibroids & 04 & 08.0 \\
\hline Adhesions & 09 & 18.0 \\
\hline
\end{tabular}

Table 4 revealed that, $16.0 \%$ of the cases had uterine septum followed by $14.0 \%$ of the cases who had $\mathrm{T}$ shaped cavity. Shaggy endometrium was found in $10 \%$ of cases followed by adhesion and polyp in 8 to $4 \%$ of cases.

Table 4: Profile of uterine factors: hysteroscopy.

\begin{tabular}{|lll|}
\hline Hysteroscopy & No. of cases & $\%$ \\
\hline Uterine septum & 8 & 16 \\
\hline T- shaped & 7 & 14 \\
\hline Adhesions & 4 & 8 \\
\hline Polyp & 2 & 4 \\
\hline Shaggy endometrium & 5 & 10 \\
\hline
\end{tabular}

According to the Table 5, 28.0\% of the cases had PCOD followed by $6.0 \%$ of the cases had Ovarian cyst and sclerotic found in $2 \%$ of cases.

Table 5: Profile of ovarian factors.

\begin{tabular}{|lll|}
\hline Ovarian factors & No of cases $(\mathbf{N}=50)$ & $\%$ \\
\hline PCOD & 14 & 28.0 \\
\hline Sclerotic & 01 & 02.0 \\
\hline Ovarian cyst & 03 & 06.0 \\
\hline Absent ovary & 01 & 02.0 \\
\hline
\end{tabular}

Table 6: Causes of infertility at laparoscopic findings.

\begin{tabular}{|lll|}
\hline Causes of infertility & No of cases $(\mathrm{N}=50)$ & $\%$ \\
\hline Uterine & 19 & 38.0 \\
\hline Tubal & 21 & 42.0 \\
\hline Ovarian & 19 & 38.0 \\
\hline Peritoneal & 20 & 40.0 \\
\hline Unexplained & 07 & 14.0 \\
\hline
\end{tabular}

As per Table 6, analysis revealed that $42.0 \%$ of the cases had Tubal causes followed by $40 \%$ of cases \& $38.0 \%$ of the cases who had peritoneal, Ovarian and uterine causes of infertility respectively in $14 \%$ of cases findings were unexplainable for the exact cause.
According to the Table 7, 78.0\% of the cases had bilateral spillage followed by $12.0 \%$ with unilateral spillage and $10.0 \%$ of the cases had no spillage.

Table 7: Profile of chromopertubation.

\begin{tabular}{|lll|}
\hline Chromopertubation & No of cases $(\mathbf{N}=50)$ & $\%$ \\
\hline Bilateral Spillage & 39 & 78.0 \\
\hline Unilateral spillage & 06 & 12.0 \\
\hline No spillage & 05 & 10.0 \\
\hline
\end{tabular}

As per above Table 8, 16 cases $(32.0 \%)$ of the cases were conceived at the end of the study and 34 cases $(68 \%)$ was not conceived.

Table 8: Profile of total conceived.

\begin{tabular}{|lll|}
\hline Out Come & No of cases & $\%$ \\
\hline Conceived & 16 & 32.0 \\
\hline Not conceived & 34 & 68.0 \\
\hline
\end{tabular}

\section{DISCUSSION}

Findings of the procedure and operative intervention if any were noted. Out of the 50 cases, 16 women conceived during the study period of 15 months. The average interval between intervention and conception was 6.3 months.

In the present study, incidence of primary infertility was $60 \%$ and that of secondary infertility was $40 \%$ which was comparable to other studies., ${ }^{2,3}$ The majority of women of primary infertility belonged to age group of 25-29 years (36.7\%) and 30-34 years while majority of those with secondary infertility belonged to age group of 30-34 years $(45 \%)$ as compared to study conducted by Sharma et al, in which majority of women with primary infertility were in age group of 21-25 years $(62.2 \%)$ while those with secondary were in age group of 26-30 years $(47.2 \%){ }^{3}$

Previous abortion was reported in majority of cases (80\%) which is comparable with studies by Sharma et al. ${ }^{3}$ Uterine factors responsible for infertility were detected in $38 \%$ of cases as compared to studies conducted by Chakraborty et al. ${ }^{4}$ The high incidence of uterine factors can be attributed to current increased use of hysteroscopy in diagnosis of uterine anomalies and there by their correction as well.

Hysteroscopy, such allowing direct visualization of the uterine cavity and cervical canal, is of help in diagnosis of abnormalities of uterine cavity as polyps, submucous myomas, and endometrial adhesions. Although hysteroscopy is the screening method to be used whenever an intrauterine abnormality is suspected, in the case of infertility HSG becomes the screening procedure, because Hysteroscopy is inadequate to assess the tubal patency. However, Hysteroscopy remains an excellent 
additional tool for evaluating the uterine characteristics in infertile women. ${ }^{5}$

Congenital uterine anomalies have been associated with pregnancy loss and obstetric complications. The most common intrauterine pathology was uterine septum $(16 \%)$. Septate uterus is associated with highest reproductive failure rate, $65 \%$ losses occurring in the first trimester. ${ }^{6}$ Surgical correction of septum improves the pregnancy outcome uterus with $80 \%$ term delivery, $5 \%$ preterm delivery, and $15 \%$ pregnancy loss. ${ }^{7}$ In present study, hysteroscopic abnormalities observed such as Uterine malformations (uterine septum - in this study) contributed to majority of cases followed by $\mathrm{T}$ shaped cavity and adhesions which was similar to other studies result. ${ }^{8,9}$

ovarian factors were responsible for $38 \%$ of cases as compared to study conducted by Chakraborty et al. ${ }^{4}$ The high incidence of PCOD can be attributed to increased awareness and diagnosis of the same. Hysteroscopic abnormalities were found in 52\% of cases which is comparable to findings of study conducted by Boudhraa $\mathrm{K}$ et al and Corson SL. ${ }^{10,11}$ Uterine malformations (uterine septum - in this study) contributed to majority of cases followed by $\mathrm{T}$ shaped cavity and adhesions. In the present study, hydrosalpinx is the major cause among the tubal factors, while bilateral tubal block and T-O mass in studies conducted by Chakraborty et al. ${ }^{4}$ In this study, tubal factors were responsible for $42 \%$ of infertility cases which is comparable to other studies. ${ }^{12-14}$

In the present study, peritoneal factors were responsible for $40 \%$ of infertility cases, with endometriosis contributing to $20 \%$ which is more than the findings in studies conducted by Sharma et al and Chakraborty et al. ${ }^{3,4}$. Pelvic adhesions were found in $18 \%$ of cases, while pelvic inflammatory disease was found in $2 \%$ of cases. Results of the present study were comparatively more than the other studies. There were no cases of active Kochs but adhesions and PID can be sequelae to prior infection. In the present study, bilateral spillage (bilaterally patent tubes) was seen in majority of cases (78\%) which is comparable to study conducted by Sharma et al. $^{3}$ In the present study, tubal factors contributed to majority of cases $(42 \%)$ followed by peritoneal factors $(40 \%)$. In this study, many cases had more than one factor responsible.

The total number of women who conceived after the procedure during the study period was $32 \%$ which was comparable to study conducted by Boudhraa $\mathrm{K}$ et al $(34.9 \%)$ while it was more as compared to that of Sharma et al $(15.83 \%))^{3,9}$ There were no intra-operative or postoperative complications in the present study.

\section{CONCLUSION}

It is concluded that while investigating the causes of female infertility combined simultaneous diagnostic laparoscopy and hysteroscopy with operative interventions wherever indicated should be performed in all infertile patients before treatment, especially in women with age more than 30 years. Many diagnostic tests for female infertility have screening value but the gold standards are laparoscopy and simultaneous hysteroscopy.

Funding: No funding sources

Conflict of interest: None declared

Ethical approval: The study was approved by the Institutional Ethics Committee

\section{REFERENCES}

1. Cunanan RG, Courey NG, Lippes J. Laparoscopic findings in patients with pelvic pain. American $\mathbf{J}$ Obstetr Gynecol. 1983 Jul 1;146(5):589-91.

2. Templeton AA, Kerr MG. An assessment of laparoscopy as the primary investigation in the subfertile female. BJOG: Int J Obstetr Gynaecol. 1977 Oct 1;84(10):760-2.

3. Sharma R; Sharma V, The infertile woman; a study of 120 cases. J Indian Med Assoc. 1991;89(2):31-2.

4. Chakraborti DK, Kole SK, Diagnostic laparoscopy in gynaecologic disorders. J Obst Gynecol. 1990;40:262-5.

5. Olivennes F, Hourvitz A, Lédée N, Gervaise A, Fernandez H, Frydman R. Should diagnostic hysteroscopy be a routine procedure during diagnostic laparoscopy in women with normal hysterosalpingography? Reprod Bio Med. 2002;4(3):256-60.

6. Homer HA, Li TC, Cooke ID. The septate uterus: a review of management and reproductive outcome. Fertil Steril. 2000 Jan 1;73(1):1-4.

7. Zhang E, Zhang Y, Fang L, Li Q, Gu J. Combined hysterolaparoscopy for the diagnosis of female infertility: a retrospective study of 132 patients in china. Materia Socio Med. 2014 Jun;26(3):156.

8. Nayak PK, Mahapatra PC, Mallick JJ, Swain S, Mitra S, Sahoo J. Role of diagnostic hysterolaparoscopy in the evaluation of infertility: A retrospective study of 300 patients. J Hum Reprod Sci. 2013 Jan;6(1):32.

9. Kamiński P, Wieczorek K, Marianowski L. Usefulness of hysteroscopy in diagnosing sterility. Polish Gynecol. 1992 Dec;63(12):634-7.

10. Boudhraa K, Jellouli MA, Kassaoui O, Ben NA, Ouerhani R, Triki A et al. Role of the hysteroscopy and laparoscopy in management of the female infertility: about 200 cases. Tunisia Med. 2009 Jan;87(1):55-60.

11. Corson SL, Cheng A, Jacqueline NG. Laparoscopy in the "normal" infertile patient: a question revisited. J Am Associat Gynecolgic Laparoscop. 2000 Aug $1 ; 7(3): 317-24$.

12. Tanahatoe SJ, Hompes PG, Lambalk CB. Investigation of the infertile couple: should diagnostic laparoscopy be performed in the infertility 
work up programme in patients undergoing intrauterine insemination?. Hum Reprod. 2003 Jan $1 ; 18(1): 8-11$.

13. Cundiff G, Carr BR, Marshburn PB. Infertile couples with a normal hysterosalpingogram. Reproductive outcome and its relationship to clinical and laparoscopic findings. J Reprod Med. 1995 Jan;40(1):19-24.

14. Tsuji I, Ami K, Miyazaki A, Hujinami N, Hoshiai H. Benefit of diagnostic laparoscopy for patients with unexplained infertility and normal hysterosalpingography findings. Tohoku J Expe Med. 2009;219(1):39-42.

Cite this article as: Kale PS, Noronha S. A prospective study to evaluate the role of hysterolaparoscopy in infertility. Int J Reprod Contracept Obstet Gynecol 2018;7:3852-6. 